\title{
Confirmation of genetic heterogeneity in familial psoriasis
}

\author{
Deborah Matthews, Lionel Fry, Anne Powles, Jean Weissenbach, Robert Williamson
}

\begin{abstract}
Psoriasis affects approximately $2 \%$ of the European population and is often familial. Linkage of a subset of psoriasis families to loci on chromosome $17 \mathrm{q}$ has recently been reported. We have studied members of a large multiply affected family from the north east of England and analysed genotypes for markers from $17 \mathrm{q}$, including the polymorphic microsatellite markers AFM210xa5, AFM163yg1, AFM044xg3, AFMa353yg1, and AFM217yd19. Two point and multipoint analysis clearly show exclusion of linkage between the telomeric region of $17 \mathrm{q}$ and psoriasis in this family. This confirms the genetic heterogeneity of psoriasis and the existence of at least one other major psoriasis locus.
\end{abstract}

( $($ Med Genet 1995;32:546-548)

Psoriasis presents with red scaly patches on the skin, characterised by epidermal hyperplasia and an inflammatory cell infiltration into both the dermis and epidermis. There is also a large increase in cytokine production. ${ }^{12}$ Maturation of keratinocytes is incomplete and cell division occurs at an earlier point in the cell cycle, resulting in skin up to 16 times the thickness of normal skin. ${ }^{3}$

Psoriasis affects about $2 \%$ of the European population. Evidence that psoriasis has a genetic component has come from studies reporting that approximately $90 \%$ of those affected have a family history of the disease, with $8 \%$ of first degree relatives and $3 \%$ of second degree relatives affected. ${ }^{45}$ Twin studies have shown a concordance rate of $70 \%$ in monozygotic twins and $23 \%$ in dizygotic twins. ${ }^{67}$

The phenotype of psoriasis is variable. There are several different clinical types; the most common form, affecting $90 \%$ of patients, is plaque forming psoriasis. However, less frequent guttate psoriasis may occur in the same family as plaque forming psoriasis. ${ }^{8}$ Five percent of psoriatics go on to develop arthritis. ${ }^{9}$

The usual age of onset of psoriasis is between 15 and 25; it may, however, occur at any age, but once present it rarely regresses. The onset may be preceded by one of several environmental triggers, including stress, change of climate, trauma to the skin and, infections, particularly streptococcal infection. ${ }^{1011}$

Various HLA associations have been reported with psoriasis. ${ }^{12-19}$ There is increased frequency of the occurrence of class I antigens
$\mathrm{B} 13, \mathrm{~B} 17, \mathrm{Cw} 6$, and $\mathrm{Cw} 7$, and class II antigens DR7 and DR4. B13, B57, and Cw6 show a particularly strong association with age of onset and family history. ${ }^{20}$ There is no evidence for linkage between the disease and HLA loci. However, the HLA associations and the fact that several treatments for psoriasis are immunosuppressive support the hypothesis that psoriasis is an autoimmune disease. ${ }^{21}$

Using a dominant model of inheritance with full penetrance, Tomfohrde et $a l^{22}$ showed a linkage of familial psoriasis to the distal end of chromosome $17 \mathrm{q}$ in a proportion of white American families. A maximum two point lod score of 5.33 was obtained in one family with marker D17S784 at a recombination value of 0.04 ; other families appeared to show exclusion, but only at full penetrance. The aim of this study was to determine if the gene predisposing to psoriasis is located on chromosome $17 \mathrm{q}$ in a large English family, or if heterogeneity of the locus for psoriasis can be confirmed in our family.

\section{Patients}

Twently seven people from one family participated in this study. Consent was obtained from all people and each was given a full medical examination. Medical histories were taken, including age of onset, treatments, and other medical conditions. On the basis of this information members of the family were assigned the following status: 12 affected, 11 unaffected, and four of unknown affected status.

Persons were designated "affected" if they had clear psoriasis lesions. Unaffected subjects have no history of the disease and no dermatological signs on physical examination. The four people in generation IV designated "unaffected status" are all over the age of 25 and have absolutely no clinical signs of psoriasis. However, the four people in the same generation designated "unknown status" have signs which indicate they may develop the disease, but which are not definitive, such as pitted nails and dry skin on the elbows and scalp.

The affected status of II. 2 is not known as he died before this study started and no clinical data are available.

\section{Methods}

The DNA was extracted from $10 \mathrm{ml}$ of blood using standard methods. ${ }^{23}$ The polymorphic markers AFM210xa5, AFM163yg1, AFM044xg3, and AFM217d10 were selected from a chromosomal map of $17 \mathrm{q} .{ }^{24}$ The se- 


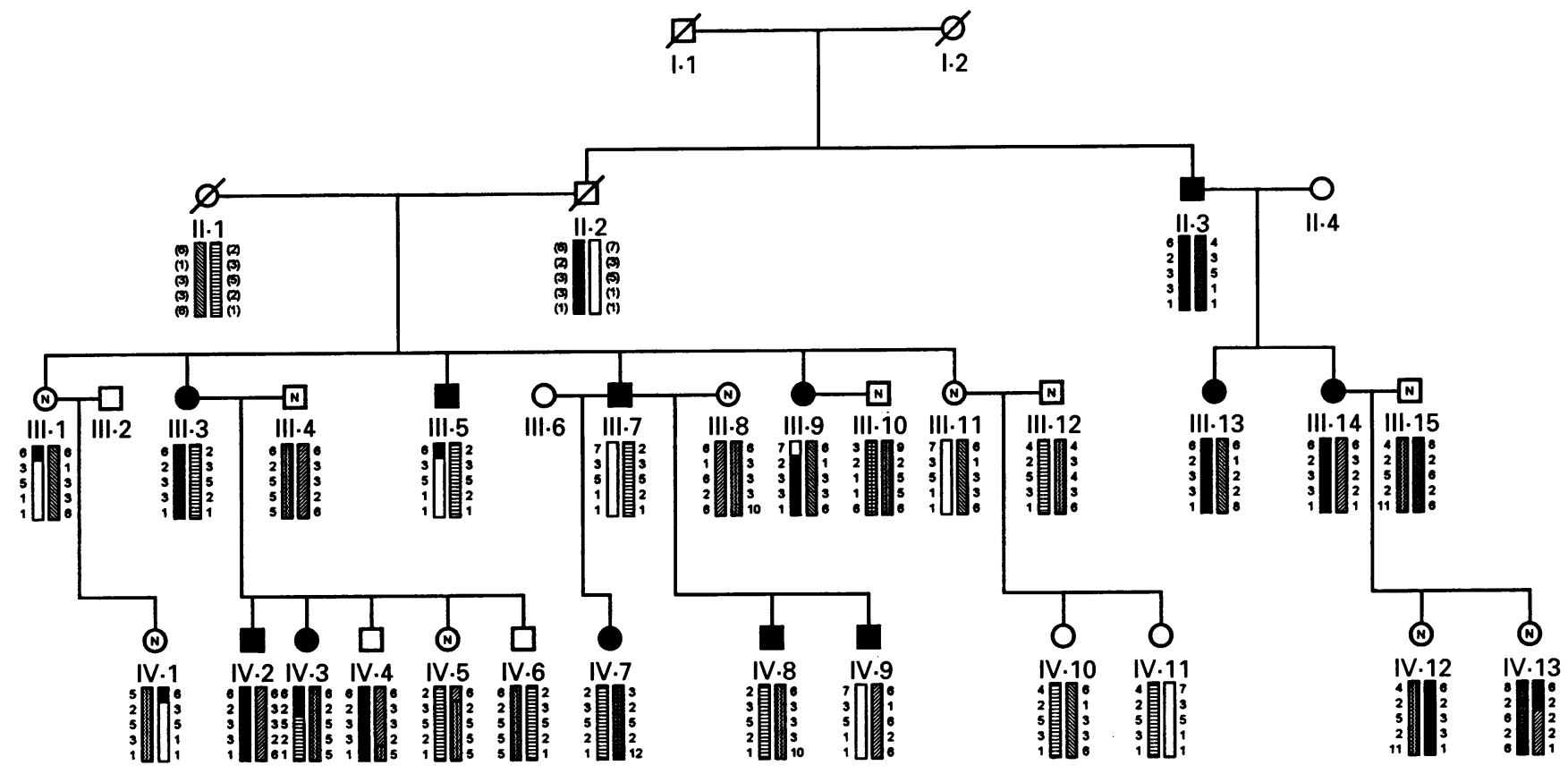

Figure 1 Chromosome 17q haplotypes. Marker order from top to bottom: AFM210xa5, AFM163yg1, AFM044xg3, AFMa353yg1, and AFM217yd10. Solid symbols: affected persons; open symbols: unknown affected status; N: unaffected persons. Inferred haplotypes are given in brackets.

quence of AFMa353yg 1 was obtained directly from Genethon, but is now available on public databases. The markers were used to genotype the family according to standard conditions. ${ }^{25}$ CEPH DNA 1347-02 was included on each electrophoresis gel as a control of allele size. The marker allele frequencies were based on the genotypes of a subset of the CEPH panel.

Familial psoriasis is assumed to be an autosomal dominant trait, although the penetrance value is unknown; the penetrance was therefore varied between 0.5 and 0.99 . The MLINK program (version $5 \cdot 2)^{26}$ was used to calculate two point lod scores between psoriasis and each individual microsatellite marker. Multipoint linkage analysis was performed using the LINKMAP program. ${ }^{27}$ The genetic map used for this was telomere-AFM217yd10-(0.11)AFMa353yg1-(0.01)-AFM044xg3-(0.04)-AFM163yg1-(0.06)-AFM210xa5. The recombination fractions between adjacent loci are in parentheses.

\section{Results}

Using markers AFM210xa5, AFM163yg1, AFM044g3, AFMa353ayg1, and AFM$217 \mathrm{yd} 10$ the patients were genotyped and haplotypes were derived. The segregation of the haplotypes within the family can be seen in fig 1.

Pairwise lod scores were generated between each marker and psoriasis. The population prevalence of psoriasis was assumed to be $2 \%$ and the penetrance was varied between 0.5 and 0.99 . The pairwise lod scores at penetrance values of $60 \%, 80 \%$, and $99 \%$ are shown in the table. The maximum lod score obtained by Tomfohrde $e^{2} a^{22}$ was 5.33 with locus D17S784 (AFM044xg3) at $4 \mathrm{cM}$ and $99 \%$ penetrance. With this family the corresponding lod score (D17S784 at $4 \mathrm{cM}$ and $99 \%$ penetrance) is $-3 \cdot 146$.

Multipoint linkage analysis on the same data produced further evidence that the psoriasis locus and the distal region of $17 q$ are not linked

Pairwise lod scores for markers AFM210xa5, AFM163yg1, AFM044xg3, AFMa353yg1, and AFM217yd10 at penetrance levels of $60 \%, 80 \%$, and $99 \%$

\begin{tabular}{|c|c|c|c|c|c|c|}
\hline \multirow[b]{2}{*}{ Penetrance } & \multirow[b]{2}{*}{ Marker } & \multicolumn{5}{|c|}{ Recombination fraction } \\
\hline & & 0.00 & 0.01 & 0.05 & $0 \cdot 10$ & $0 \cdot 20$ \\
\hline 0.99 & $\begin{array}{l}\text { AFM210xa5 } \\
\text { AFM163yg1 } \\
\text { AFM044xg3 } \\
\text { AFMa353yg1 } \\
\text { AFM217yd10 }\end{array}$ & $\begin{array}{r}-6.481 \\
-2 \cdot 673 \\
-4 \cdot 463 \\
-5.345 \\
0.085\end{array}$ & $\begin{array}{r}-5 \cdot 101 \\
-2 \cdot 236 \\
-4 \cdot 063 \\
-3 \cdot 120 \\
0 \cdot 111\end{array}$ & $\begin{array}{r}-2.715 \\
-1.060 \\
-2.865 \\
-2.091 \\
0.172\end{array}$ & $\begin{array}{r}-1.575 \\
-0.443 \\
-1.829 \\
-1.456 \\
0.196\end{array}$ & $\begin{array}{r}-0.604 \\
0.026 \\
-0.791 \\
-0.557 \\
0.163\end{array}$ \\
\hline $0 \cdot 80$ & $\begin{array}{l}\text { AFM210xa5 } \\
\text { AFM163yg1 } \\
\text { AFM044xg3 } \\
\text { AFMa353yg1 } \\
\text { AFM217yd10 }\end{array}$ & $\begin{array}{r}-2.615 \\
-1.074 \\
-2.047 \\
-1.735 \\
0.089\end{array}$ & $\begin{array}{r}-2.48 \\
-0.999 \\
-1.887 \\
-1.049 \\
0.105\end{array}$ & $\begin{array}{r}-1.761 \\
-0.709 \\
-1.516 \\
-0.595 \\
0.144\end{array}$ & $\begin{array}{r}-1 \cdot 166 \\
-0.399 \\
-1 \cdot 179 \\
-0.499 \\
0 \cdot 157\end{array}$ & $\begin{array}{r}-0.507 \\
-0.051 \\
-0.606 \\
-0.360 \\
0.126\end{array}$ \\
\hline 0.60 & $\begin{array}{l}\text { AFM210xa5 } \\
\text { AFM163yg1 } \\
\text { AFM044xg3 } \\
\text { AFMa353yg1 } \\
\text { AFM217yd10 }\end{array}$ & $\begin{array}{r}-1.786 \\
-0.543 \\
-1.476 \\
-1.089 \\
0.100\end{array}$ & $\begin{array}{r}-1 \cdot 710 \\
-0.525 \\
-1.338 \\
-0.681 \\
0.108\end{array}$ & $\begin{array}{r}-1.266 \\
-0.434 \\
-1.034 \\
-0.319 \\
0.126\end{array}$ & $\begin{array}{r}-0 \cdot 865 \\
-0 \cdot 296 \\
-0 \cdot 812 \\
-0 \cdot 265 \\
0 \cdot 127\end{array}$ & $\begin{array}{r}-0.405 \\
-0.079 \\
-0.456 \\
-0.263 \\
0.095\end{array}$ \\
\hline
\end{tabular}




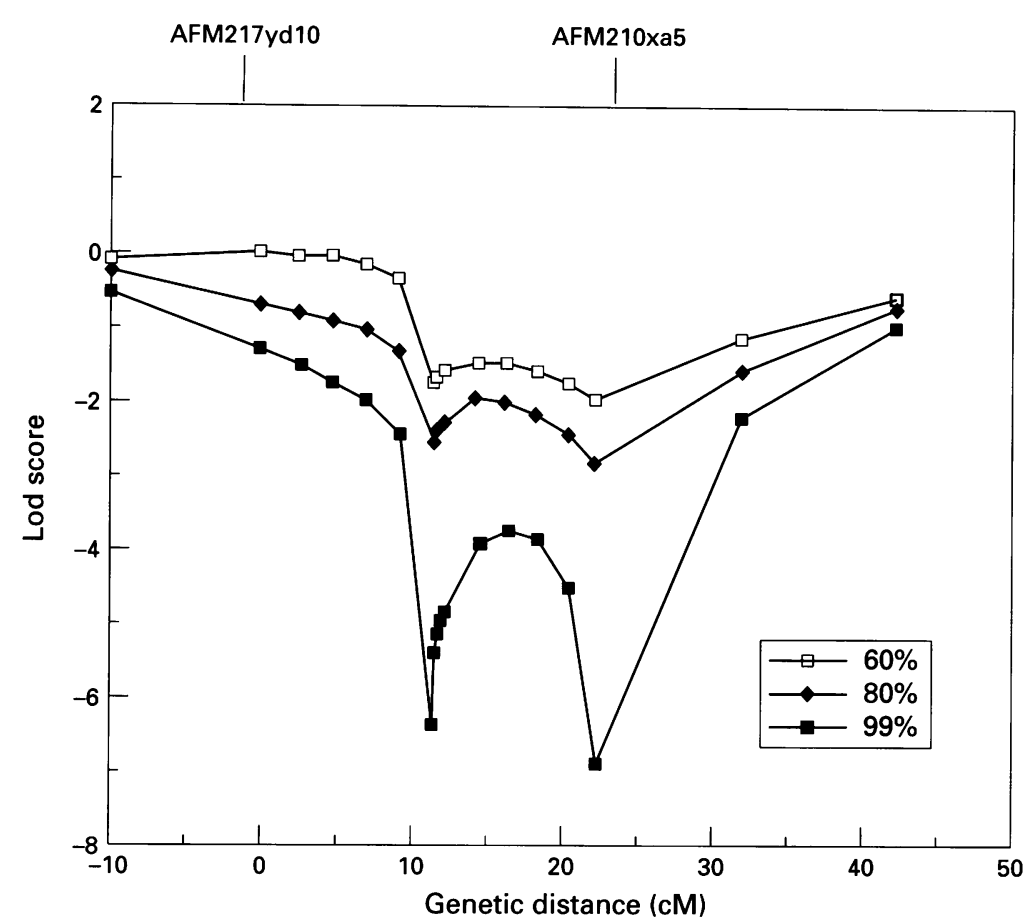

Figure 2 Multipoint exclusion maps of the distal region of $17 q$ at $60 \%, 80 \%$, and $90 \%$ penetrance.
We thank all the patients who participated in this study, particularly Thomas Cockburn for his help in contacting and organising the family members, and Dr Jean Weissenbach for marker sequence data in advance of publication. This study was supported by Eurogem.

1 Baker B, Fry L. The immunology of psoriasis. Brf Dermatol 1991;126:1-9.

2 Menter A, Barker J. Psoriasis in practice. Lancet 1991;338: 231-4.

3 Valdimarson H, Barker B, Jonsdittis I, Fry L. Psoriasis, a disease of abnormal keratinocyte proliferation induced by T lymphocytes. Immunol Today 1986;7:256-9.

4 Lomholt G. Psoriasis: prevalence, spontaneous course and genetics. Copenhagen: GEC Gad, 1963.

5 Hellgren I. Psoriasis. Stockholm: Almquist and Wiksell, 1967.

6 Brandrup F, Holm N, Grunn N, et al. Psoriasis in monozygotic twins: variations in expression in individuals with genetic constitution. Acta Dermatol Venereol 1982;62:229 36.

7 Farber E, Nall I, Watson W. Natural history of psoriasis in 61 twin pairs. Arch Dermatol 1974;109:207.

8 Fry L. Atlas of psoriasis. The Panthenon Publishing Group, 1992.

9 Krueger G, Bergstresser P, et al. Psoriasis. F Am Acad Dermatol 1984;11:937-47.

10 Powles A, Baker B, Rutman A, et al. Epidermal rupture is the initiating factor for the Koebner response in psoriasis. the initiating factor for the Koebner resp
Acta Dermatol Venereol 1990;70:35-8.

11 Norlind R. Significance of infections in origin of psoriasis. Acta Rheumatol Scand 1953;1:135-44.
. Signifance of infections in

12 Russell T, Schultes L, Kuban D. Histocompatibility (HLA) antigens associated with psoriasis. N Engl F Med 1972; 287:738-43

13 Svejgaard A, Nielsen L, Svejgaard E, et al. HLA in psoriasis vulgaris and in pustular psoriasis-population and family studies. Br $\mathcal{F}$ Dermatol 1974;91:145.

14 Karvonen J, Tiilikainen A, Lassus A. HLA antigens in psoriasis: a family study. Ann Clin Res 1976;8:298-304.

15 Tiilikainen A, Lassus A, Karovnen J, et al. Psoriasis and HLA Cw6. Br $¥$ Dermatol 1980;192:179.

16 Tiwari J, Lowed N, Abramovitis W, Hawkins B, Park M. Association of psoriasis with HLA-DR7. $\mathrm{Br} \mathcal{f}$ Dermatol 1982;106:227-30.

in this family. The program Linkmap was used to perform likelihood calculations on fitting the psoriasis locus into the intervals on the $17 q$ map. Fig 2 is the exclusion map produced. The three maps were calculated for $60 \%, 80 \%$, and $99 \%$ penetrance.

\section{Discussion}

Our data show that psoriasis is not linked to the $17 \mathrm{q}$ region in this family. This confirms that familial psoriasis is a genetically heterogeneous disease with at least two loci involved, one at $17 q$ and one other. The result is not surprising as it is in agreement with population studies which concluded that the inheritance of psoriasis could not be explained as a simple dominant disorder resulting from mutations at one locus. ${ }^{28-30}$

The large clinical variation observed with psoriasis can also be more easily explained if psoriasis is caused by mutations at more than one gene. Whether the two or more genes involved act independently or whether epistasis is involved is yet to be determined. 